\title{
High impact crystallography skills development through local undergraduate curriculum and regional workshops and schools
}

\author{
L. Dawe \\ Wilfrid Laurier University, Department of Chemistry and Biochemistry, 75 University Ave. W. Waterloo, ON, Canada, N2L 3C5 \\ ldawe@wlu.ca
}

Resources to develop high impact skills in diffraction data collection and interpretation can be limited by facility access, expert availability, and the budgetary requirement to meet a critical mass of participants before it becomes practical to offer instruction. At the local level, shared resources between institutions, as well as curriculum approaches that incorporate scaffolding practices from first year general chemistry to senior undergraduate capstone courses, can be employed to equip trainees with skills in structural science.[1] Looking to the regional and (inter)national level, the Canadian National Committee for Crystallography (CNCC) [2] sponsors the annual Canadian Chemical Crystallography Workshop (CCCW) and the Canadian Powder Diffraction Workshop (CPDW), both which have now past their first decades of instruction. Several hundred trainees from Canada, and well beyond (for example, the US, UK, and Brazil) have participated in these opportunities.

As a university instructor, the organizer for CCCW2019 - 2021, and an administrative supporter of CPDW, my presentation will highlight (1) the diversity of experiences that attendees have, (2) logistical aspects of organizing and teaching in these various ventures, with a look at the transition to remote delivery for CCCW2020 and 2021, amid the current pandemic, and (3) I will share some insights and results from past trainees whose research practices have been transformed as a result of these learning opportunities.

[1] Gražulis, S., Sarjeant, A. A. Moeck, P., Stone-Sundberg, J., Snyder, T. J., Kaminsky, W., Oliver, A. G., Stern, C. L., Dawe, L. N., Rychkov, D. A., Losev, E. A., Boldyreva, E. V., Tanski, J. M., Bernstein, J., Rabeh, W. M. \& Kantardjieff, K. A. (2015) Crystallographic Education in the 21st Century. J. Appl. Crystallogr. 48, 1964.

[2] Canadian National Committee for Crystallography: https://xtallography.ca/

Keywords: crystallography education; crystallography workshops; crystallography in Canada 